\title{
ASSESSMENT OF SELECTED BARLEY PLANTS, IN A PROGRAM OF ARTIFICIAL MUTATION IN THE FOURTH GENERATION
}

(Received:21.3.2012)

\author{
By \\ J.R. Saleh, M. Shaherly and S. Lawand \\ Department of Agronomy, Faculty of Agriculture, Damasus University, Syria
}

\begin{abstract}
The present investigation was carried out at Abo Jarsh farm and in the laboratory of Agronomy Department- Faculty of Agriculture-Damascus University during the growing season 2010-2011. Seeds of barley (Forat 1 and Arabic Black varieties) were exposed to Gamma Ray at 5, 10 and 15 Kilorad dose at the Atomic Energy Commission in 2006.

The aim was to evaluate the quantitative traits and yield components of mutant plants of the fourth generation, those were selected from previous generations on the basis of quantitative and morphological changes, i.e. transition spikes of six-rows into two-rows, and transition of spikes from two-rows to sixrows, early and late heading, and short plants. Correlation between quantitative traits were studied.

The mutated lines performed significantly better in all the studied traits as compared to the control especially in the yield component traits. Treating with the dose of 5 kilorads resulted in a higher number of mutant lines compared to other doses. Forat 1 variety was greatly affected by the rays and resulted in four types of mutants as compared to Arabic Black variety, that resulted in a single mutant.
\end{abstract}

Key words: assessment, barley, fourth generation, mutation,.

$$
\begin{aligned}
& \text { تقييم نباتات منتخبة من الثعير في برنامج الطقرات الصناعية في الجيل الرابع } \\
& \text { جمال رفيق صالح - مخلص شاهرلي - سلام لاوند } \\
& \text { قسم المحاصيل الحقلية_ كلية الزر اعة- جامعة دمشق- سوريا } \\
& \text { ملخص } \\
& \text { نفذ هذا البحث في مزر عة أبي جرش وفي مخابر قسم المحاصيل الحقلية في كلية الزر اعة بجامعامعة دمثنق للموسم }
\end{aligned}
$$

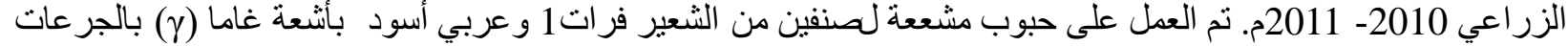

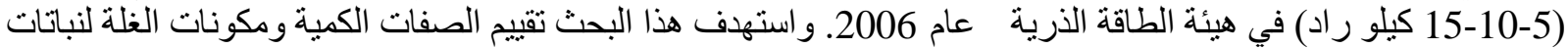

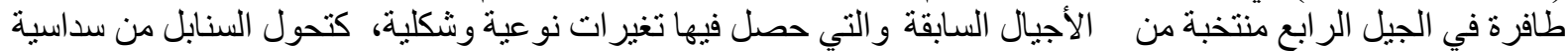

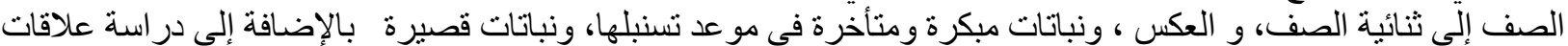

$$
\begin{aligned}
& \text { الارتباط بين الصفات الكمية المدروسة. }
\end{aligned}
$$

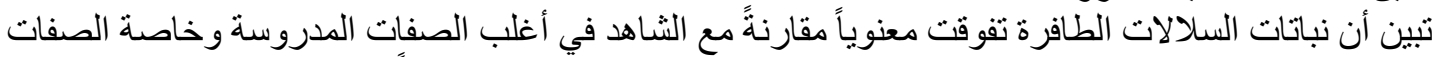

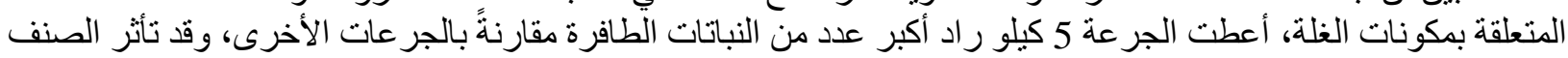

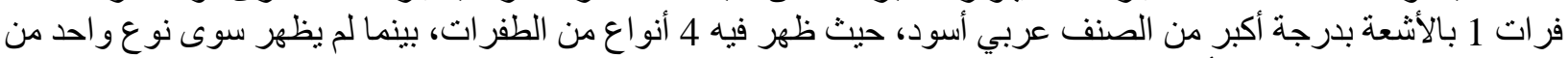

$$
\begin{aligned}
& \text { الطفر ات في الصنف عربي أسود. } \\
& 2576 \text { كغ/هـ، و الإنتاج الكلى نحو } 123.47 \text { مليون طناً }
\end{aligned}
$$

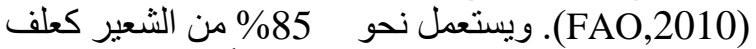

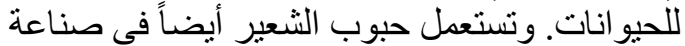

$$
\begin{aligned}
& \text { المولت Malt ، و إنتاج النشا وبعض الصنات الصناعات الكيميائية }
\end{aligned}
$$

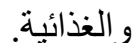

$$
\begin{aligned}
& \text { تقدر المساحة الإجمالية المزروعة بمحصول الثعير فى }
\end{aligned}
$$

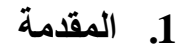

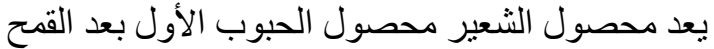

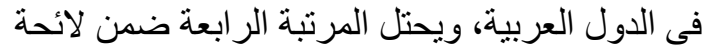

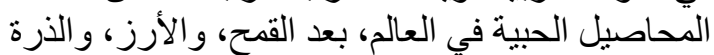

$$
\begin{aligned}
& \text { الصفر اء. وتقدر المساحة المزروعة علئ عالمباً } \\
& \text { الثعير بنحو } 47.89 \text { مليون هكتار أ، والإنتاجية قرابة }
\end{aligned}
$$


الأصناف تم الحصول عليها في بر امج طفر ات صناعية استخدمت فيها الأشعة المختلفة (استخدام التقنيات النوات النورية في

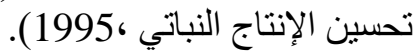
تعد الطفرات من إحدى العو المل الأبناج الأساسية في التطور

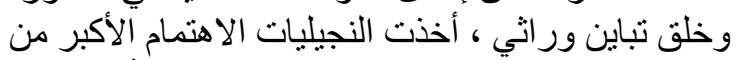

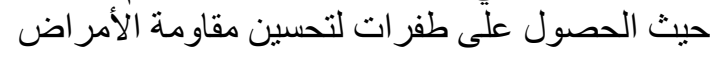

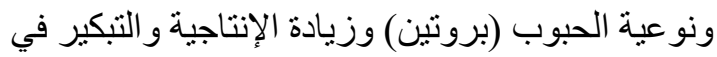
النضج ومقاومة الضجعان (ساق قصيرة وقاسية) (Lundqvist et al., 1991) تم الحصول على طفر ات متحملة للملوحة في الثعير من

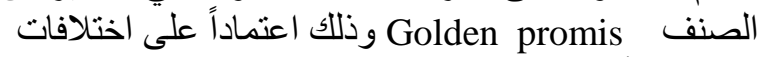
محتوى الأوراق من الصوديوم (Förster et al., 1994).

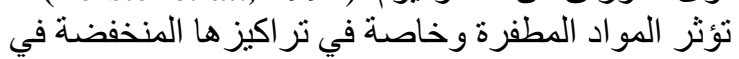

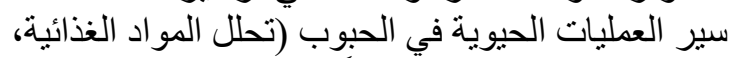

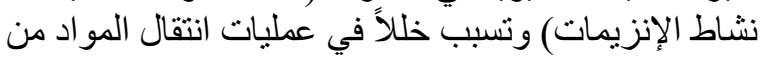

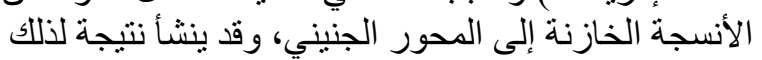
مركبات جديدة نؤثر في حيوية الخلايا النباتية .(Chen, 1996)

تم معاملة بذور نقية لعدة أصناف من القمح الطري

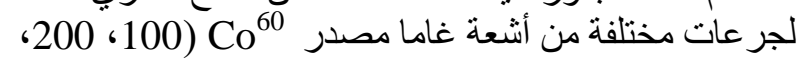
300، 400 Gy

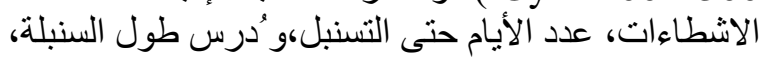

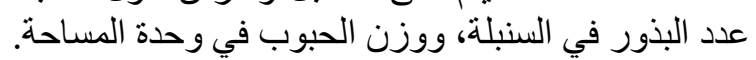

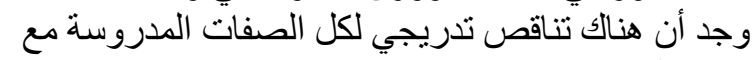
زيادة الجر عة ما عدا عدد الآشطاءات لترات الهنات

(Maluszynski et al., 1987, Irfaq and Nawab,

لم تؤد المعاملة بأثنعة غاما بين Koksel et تأثير في عملية تخمير البذور في الثعير فالثير al.,1998)

Vrs1 انتخبت نباتات سداسية الصف و الحاملة للمورثية

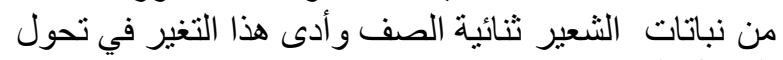

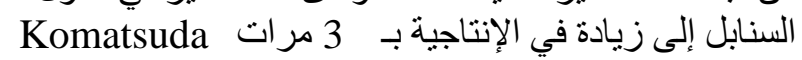
(et al ., 2007)

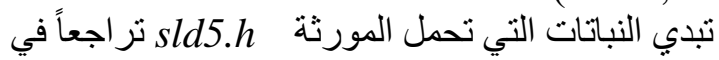

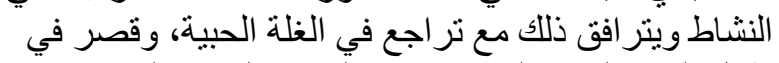

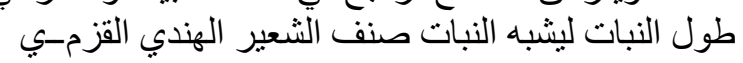
(Pozzi et al., 2003)

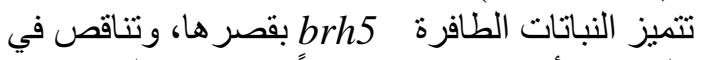

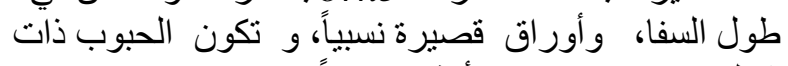

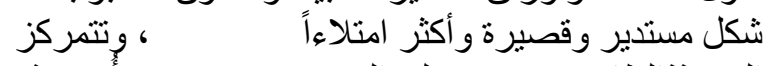
المورثةالطافرة

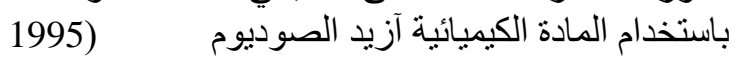
.Franckowiak تلتميز النباتات بوجود المورثة

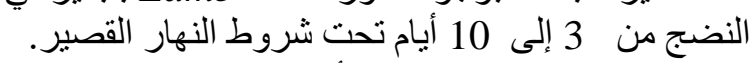
ويتر افق ذلك مع قو ام قصير. و وأثار الباحثون إلى إن هذه النه
الدول العربية بنحو 5.62 مليون هكتار ، والإنتاجية 1.02

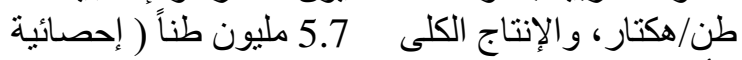

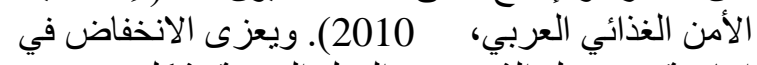

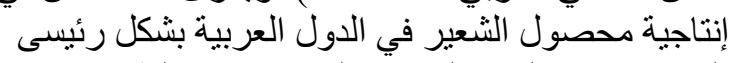
إلى عدم توفر المادة الور اثثية المحسنة ذات الات الطاقة الإنتاجية بكاية

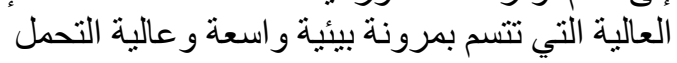

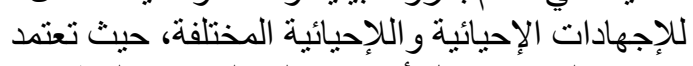

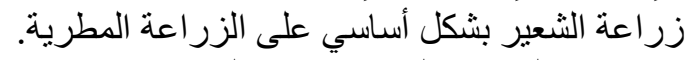

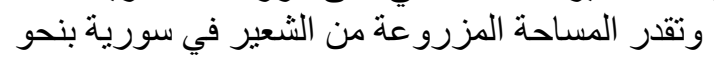

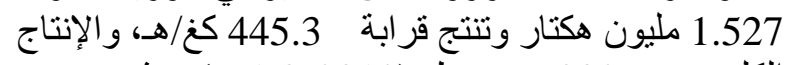

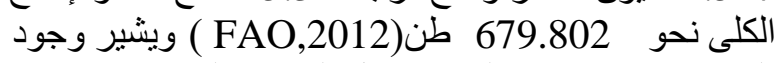

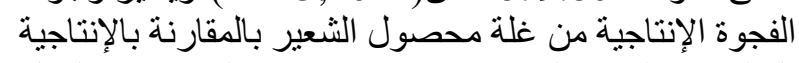

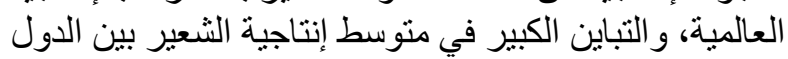

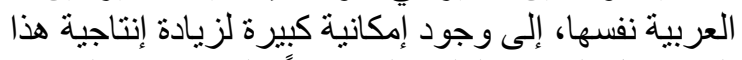

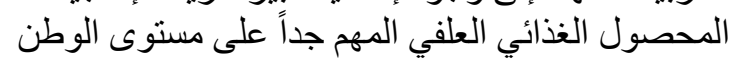

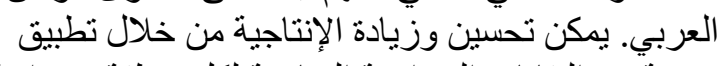

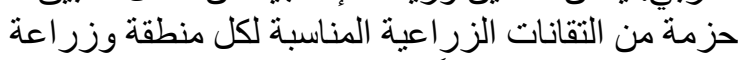

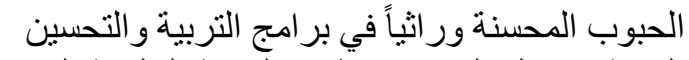

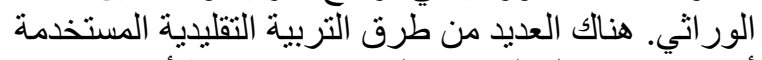

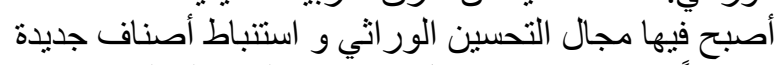

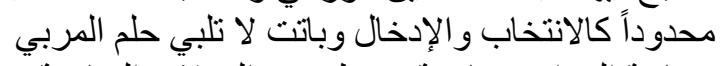

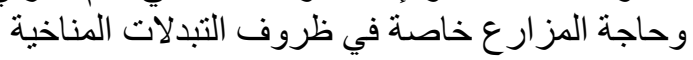

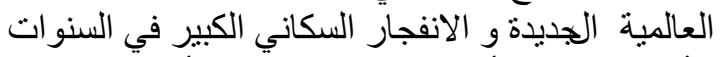

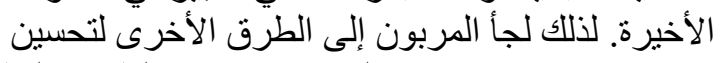

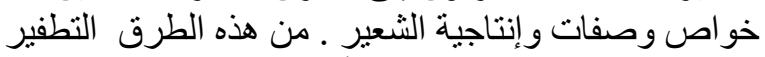

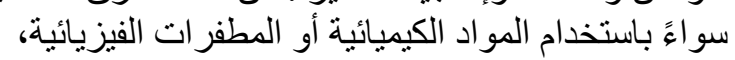

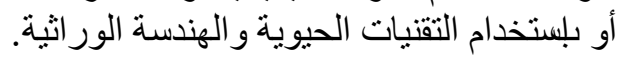

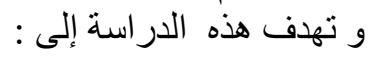

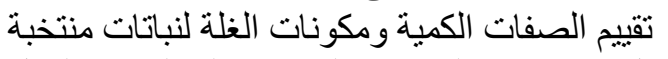

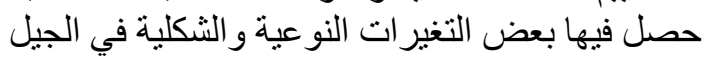

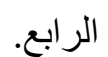

1.1.دراسة علاقات الارتباط بين الصفات المدروسة

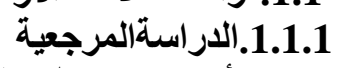

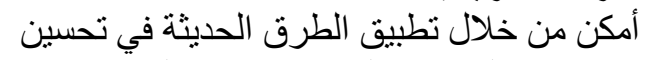

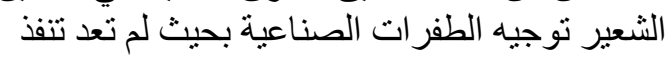

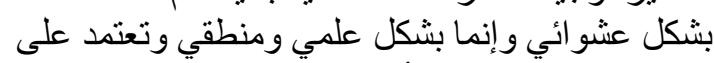

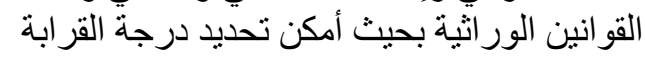

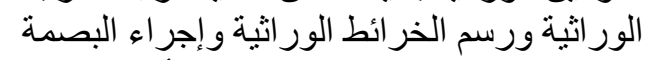

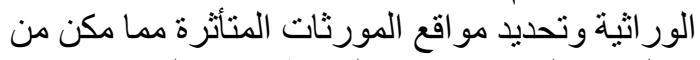

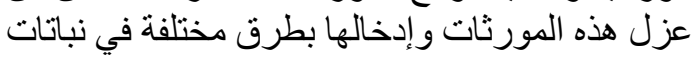

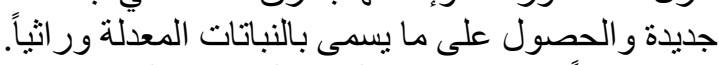

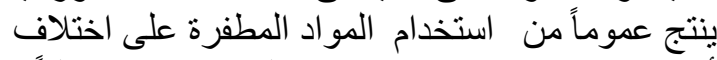

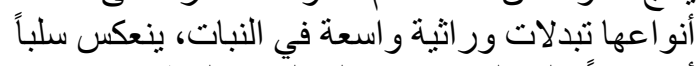

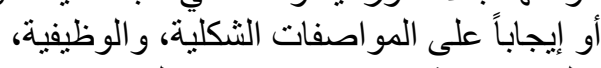

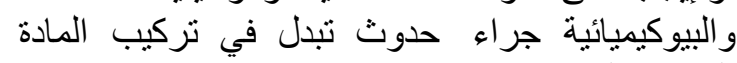

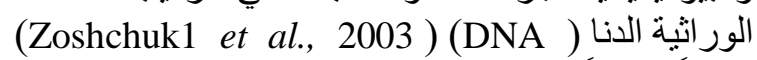
وخلاً صبغياً (شاهرلي و العودة ، 2002).

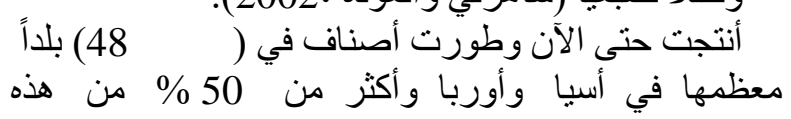


- نباتات متأخرة النضج تحت تأثير الجرعة (5 كيلور اد) في الصنف فرات 1.

3.2. طريقة الزراعة Planting method:

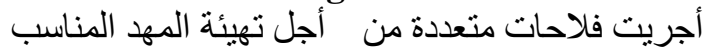
و التخلص من الأعشاب الضارة و أضيفت الأسمدة المعدنية (N.P.K)

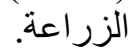

زر عت الحبوب في الحقل في أربعة سطور، طول كل

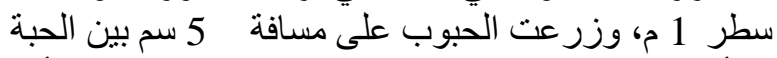

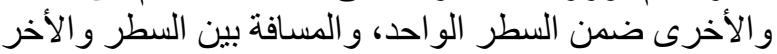

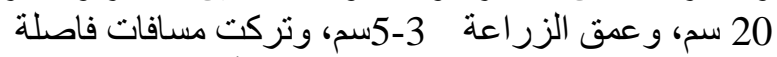

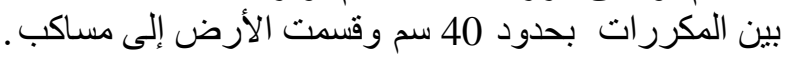

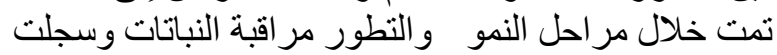

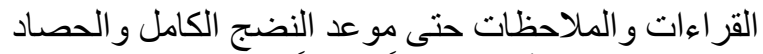
فى 2011/5/8، أعطيت رياً تكميلياً كلما استدعت الكاعل الحاجة.

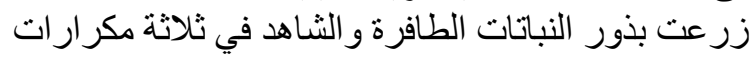
بطريقة القطاعات العشو ائية الكاملة (R.C.B.D).

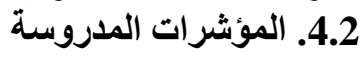

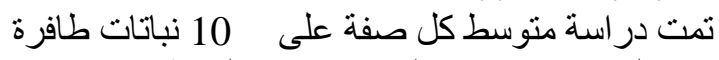
أخذت بشكل عشو ائي ومن المنتصف في كلى عل قطعة تجربييــة

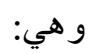

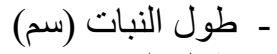

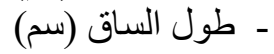
ـ - عدد الاشطاءات الكلية ـ عدد الاشطاءات المثمرة- طول السبة السنبلة الرئيسية (سم)

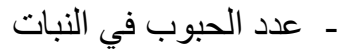
- وزن الحبوب في النبات (غ النبات - وزن الألف حبة (غ في النيات

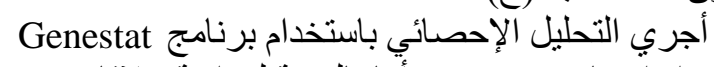

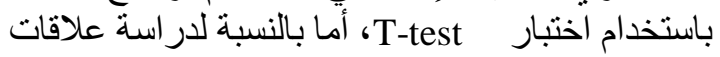
الارتباط بين الصفات المدروسة فقد استخدم البرنامج 17 . SPSS

\section{3. النتائج والمناقشة}

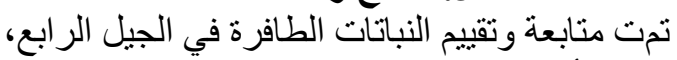

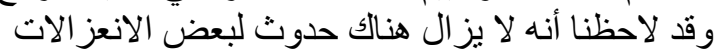

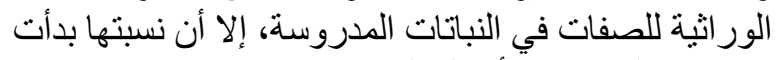

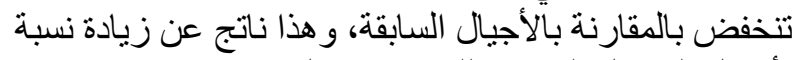

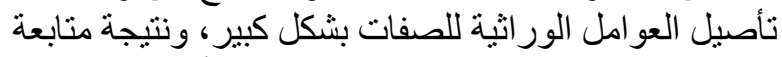

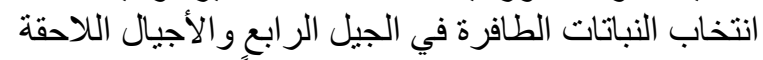

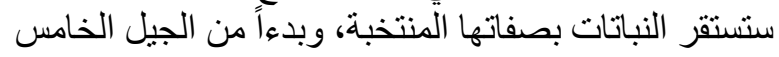

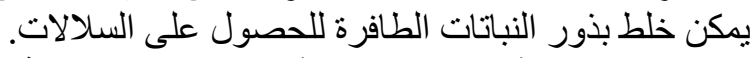

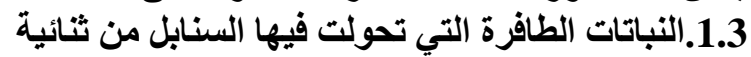

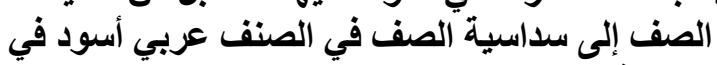
الجرعة (15 كيلوراد)

بينت نتائج التحليل الإحصائي وجود فرودات فروقات معنوية
المورثة منمركزة على الصبغي 5HL و عزلت من الثعير الهندي القزمي (Jain, 1961; Sears et al., 1981).

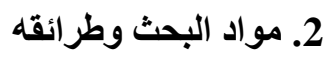

1.2. مكان تنفيذ البحث

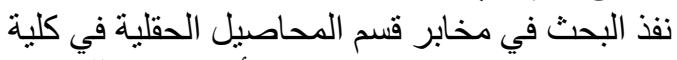

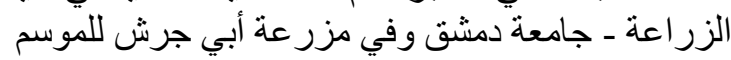

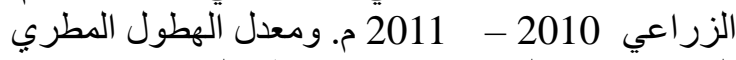

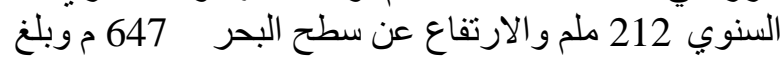

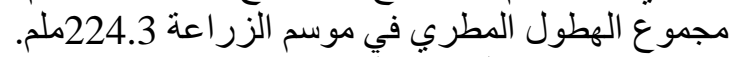

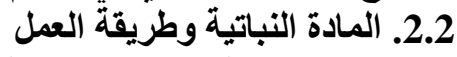

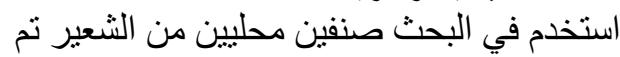

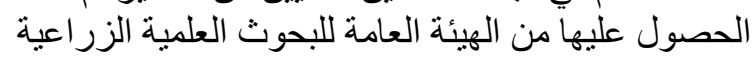
في سورية.

(1.2.2. مربي أسود

صنف محلي قديم، ثنائي الصف، لون الون حبوبه سبه سوداء

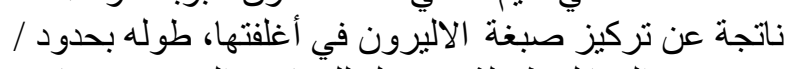

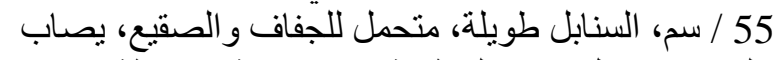
بالرقاد في حال زيادة الرطوبة ولية وذو إنتاجية متوسطة.

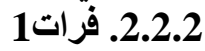

سداسي الصفوف، انت ج محلياً من قبل الهيئة العامة

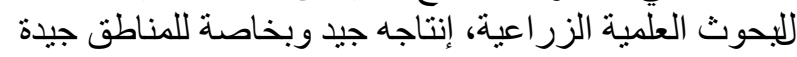
الهطول، منوسط القدرة على الاشطاء، منوسط التحمل التحل

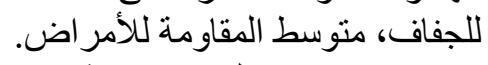

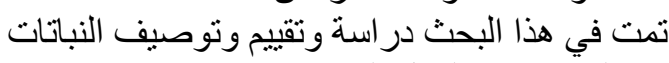

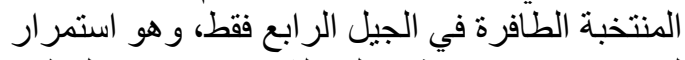

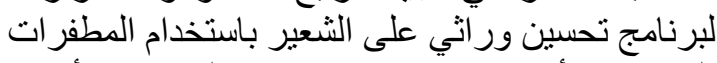

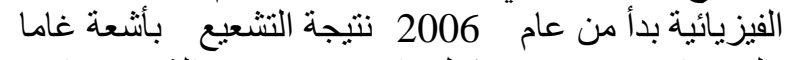
بالجر عات (5-10-15 كيلور اد) في صنفي الثئية الشعير فرات 1

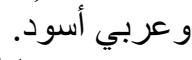

تمت معاملة البذور في هيئة الطاقة الذرية لكل من ون

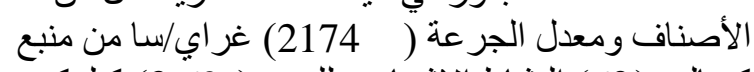

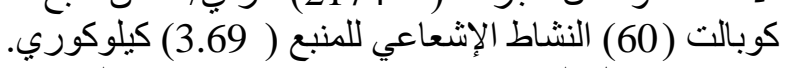

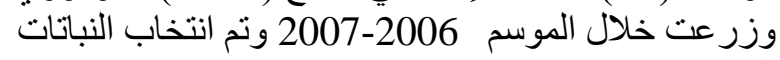

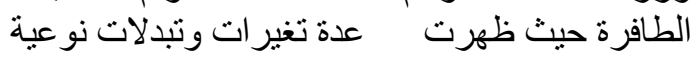

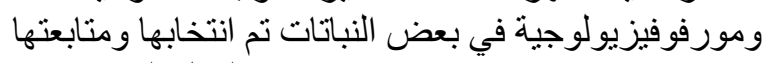

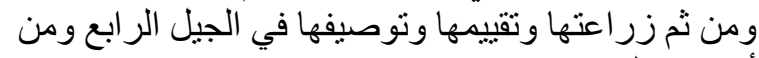

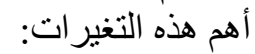

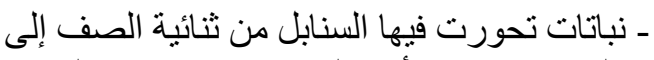

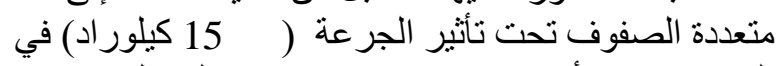

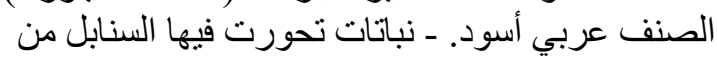

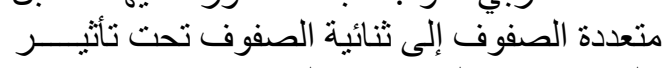

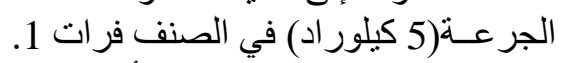

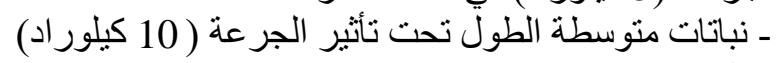
في الصنف فرات 1. - نباتات مبكرة النضج تحت تأثنير الجرعة ( 5 كيلور اد) في الصنف فرات 1. 
3.3. العلاقات الارتبارطية بين الصفات:

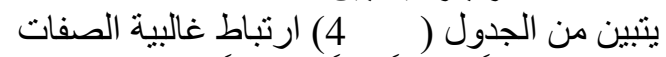

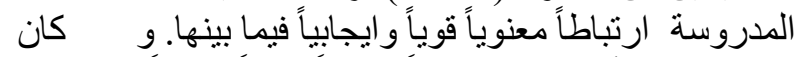

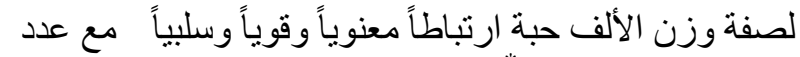

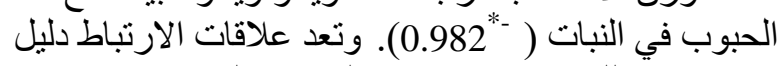

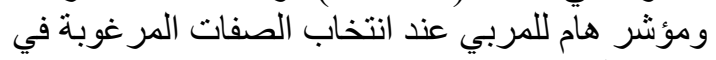
بر امج التربية.

3.3 1. نباتات السلالة التي تحولت فيها السنابل من سداسية

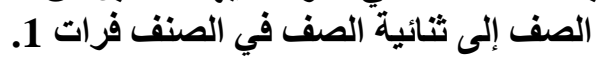

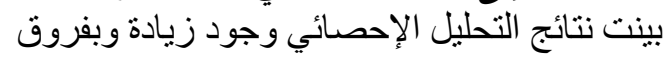

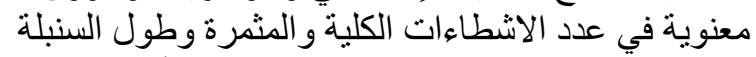

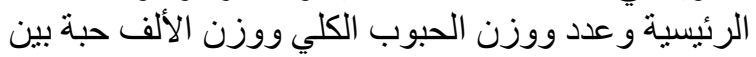

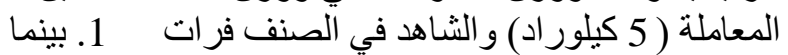

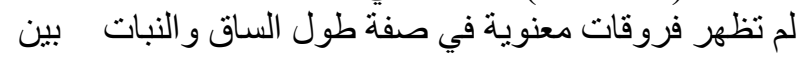

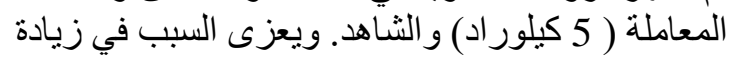

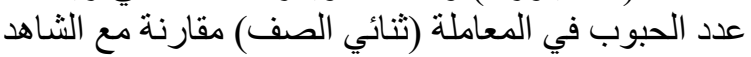

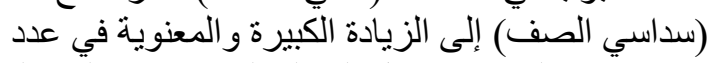

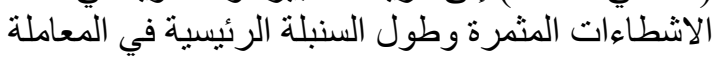

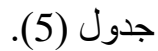

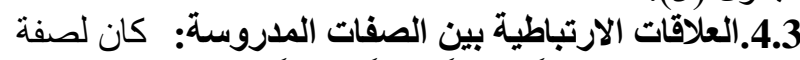

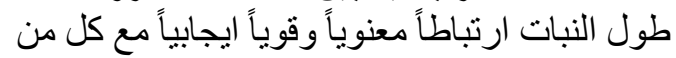

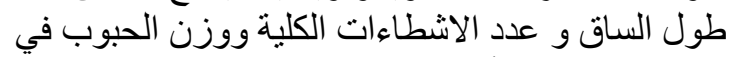
النبات ووزن الألف حبة حيث بلغ (

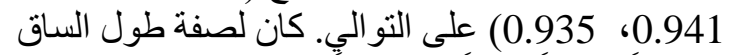

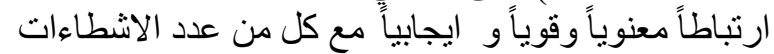

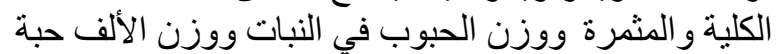

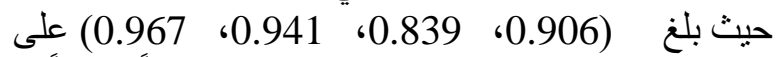
التو الي. وارتبط عدد الاشطاءات المثنمرة ارتباطاً معنوياً

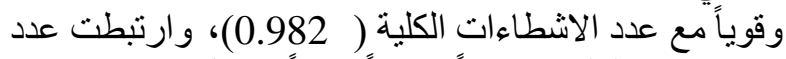

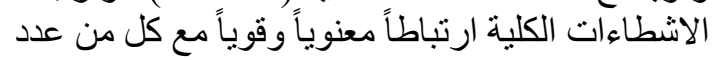
ووزن الحبوب في النبات(

وكان لصفة وزن الحبوب النبات في النبات ارتباطاً معنوياً وقوياً

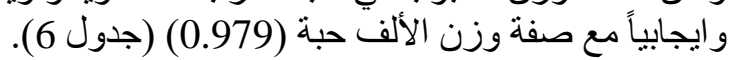

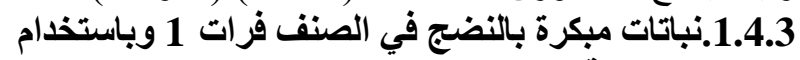

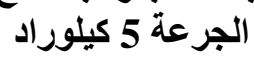

بينت نتائج التحليل الإحصائي وجود التود زيادة وبفروقات

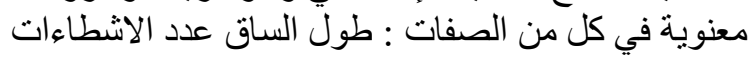

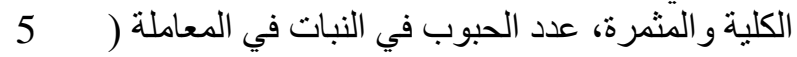

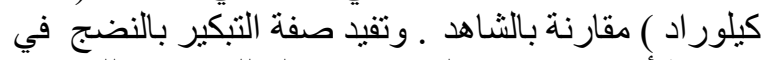

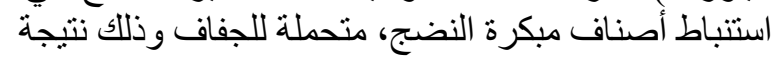

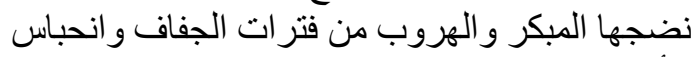

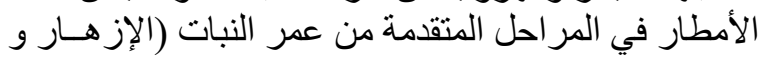

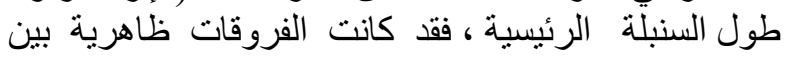

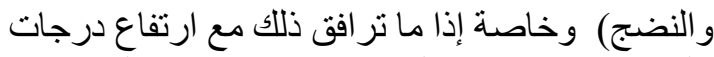

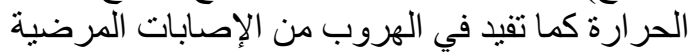

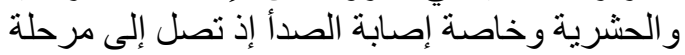

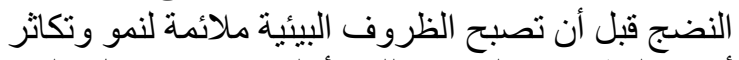

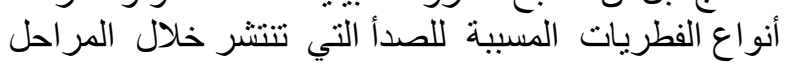

في صفات عدد الحبوب في النبات ووزن الألف حبة بين

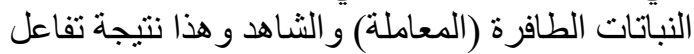

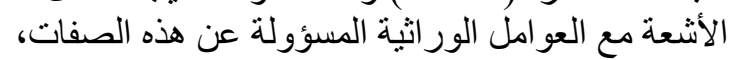

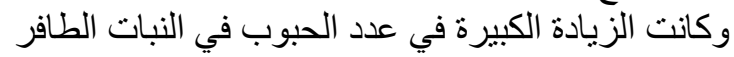

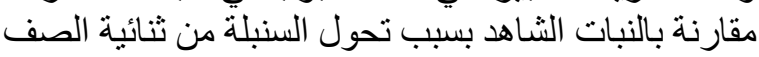

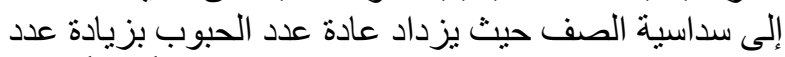

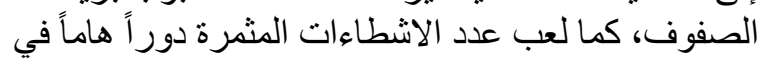

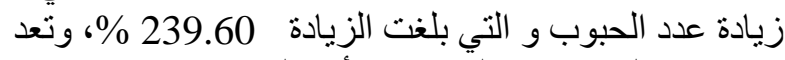

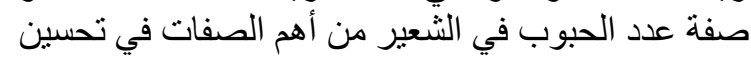

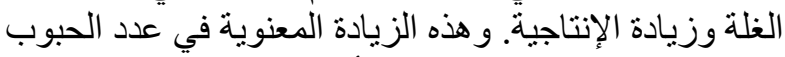

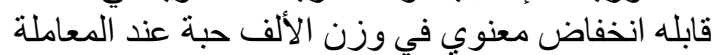

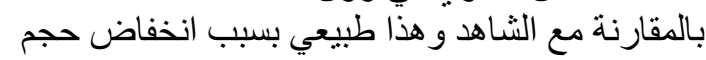
الحبوب مع زيادة عددها الكبير.

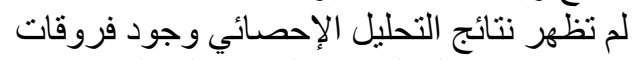

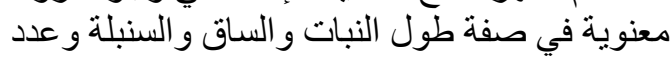

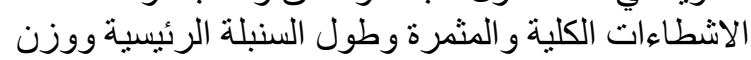

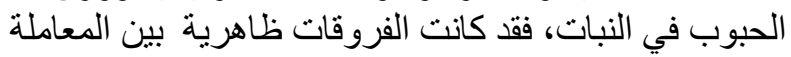
(15 كيلور اد) و الثاهد جدول (1).

جدول(1): تحول السنبلة من ثنائية الصف إلى سداسية الصف في الصنف

\begin{tabular}{|c|c|c|c|}
\hline المغنويلة & كيلوراد 15 & الثشاهد & المعيار \\
\hline 0.682 & 82 & 79 & طول النبات \\
\hline 0.711 & 74.33 & 72.33 & طول الساق \\
\hline 0.414 & 21.66 & 23 & عدد الاشطاءات الكلية \\
\hline 0.157 & 19.66 & 16 & عدد الاشطاءات المثمرة \\
\hline 0.519 & 7.66 & 7.33 & طول السنبلة الرئيسية \\
\hline 0.003 & *489.33 & 204.33 & عدد الحبوب في النبات \\
\hline 0.072 & 11.52 & 8.73 & وزن الحبوب في النبات \\
\hline 0.040 & *23.49 & 44.03 & وزن الألف حبة \\
\hline
\end{tabular}

2.3.العلاقات الارتباطية بين الصفات المدروسة:

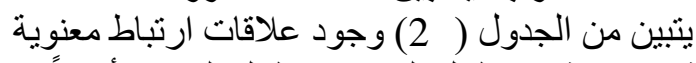
وقوية و موجبة بين طول الساق مع طول طول النبات و وأيضاً بين

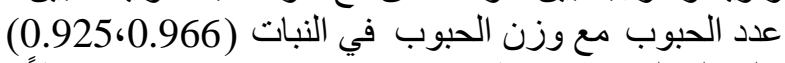

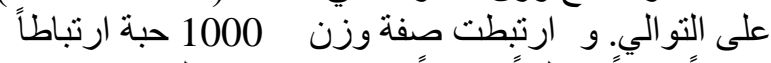

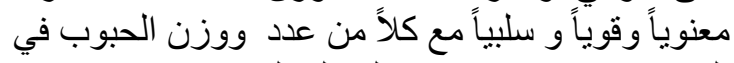

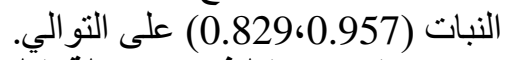

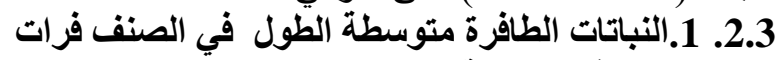
1 في الجرعة (10 كيلوراد)

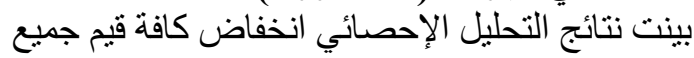

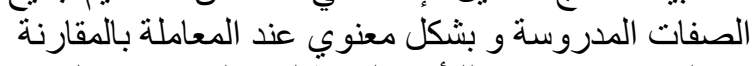

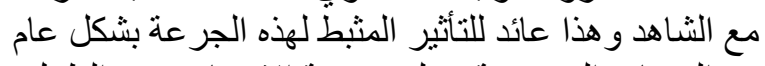

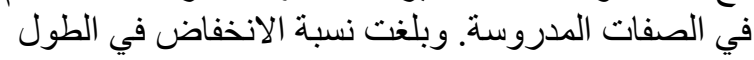

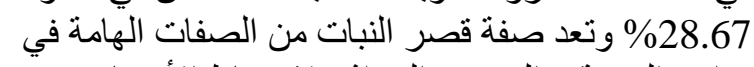

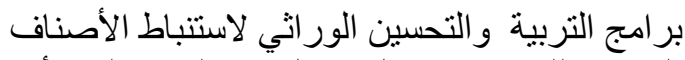

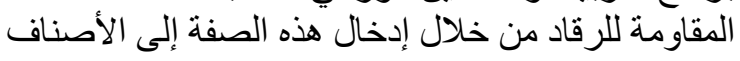

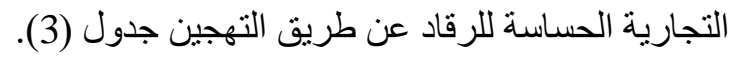


جدول (2): العلاقات الارتباطية بين الصفات المدروسة في نباتات الصنف عربي أسود تحت تأثير الجرعة (15 كيلوراد).

\begin{tabular}{|c|c|c|c|c|c|c|c|c|}
\hline المعيار & طول النبات & طول السات & طول السينبلة & 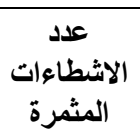 & الاشطاءعات & في النبات & الحبوب في & وزن 1000 \\
\hline طول النبات & 1 & & & & & & & \\
\hline طول الساق & $0.996^{*}$ & $\mathbf{1}$ & & & & & & \\
\hline طول السنبلة الرئيسية & 0.483 & 0.404 & 1 & & & & & \\
\hline عدد الاثططاءات المثمرة & 0.588 & 0.558 & 0.561 & 1 & & & & \\
\hline عدد الاشطاءات الكلية & 0.389 & 0.386 & 0.209 & 0.364 & 1 & & & \\
\hline عدد الحبوب في النبات & 0.134 & 0.107 & 0.330 & 0.779 & 0.229 & 1 & & \\
\hline وزن الحبوب في النيات & $0.010-$ & $0.047=$ & 0.363 & 0.772 & 0.006 & $0.925^{*}$ & 1 & \\
\hline وزن 1000حبة & 0.176- & 0.153- & $0.312-$ & $0.775-$ & 0.229 & 0.957-* & 0.829-* & 1 \\
\hline
\end{tabular}

5.3.العلاقات الارتباطية بين الصفات المدروسة:

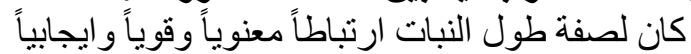

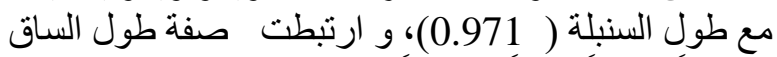

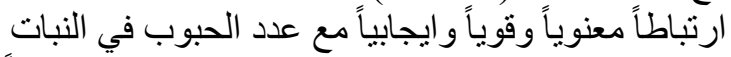

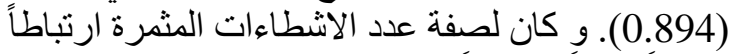

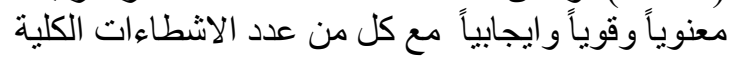

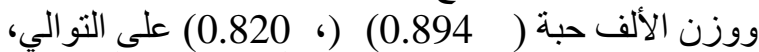
وارتبطت صفة طول السنبلة ارتباطاً معنوياً وقوياً و ايجابياً الإلياً

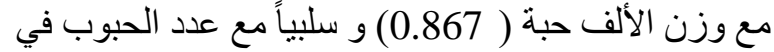

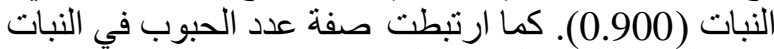

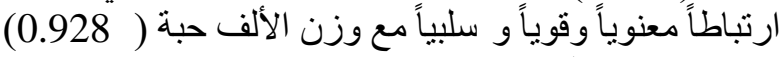

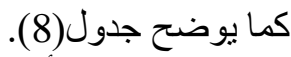

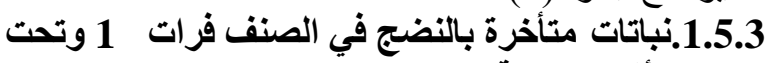

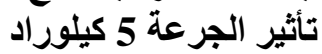

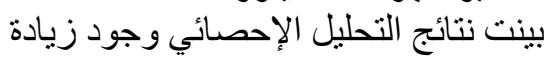

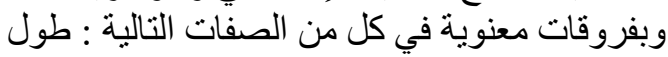

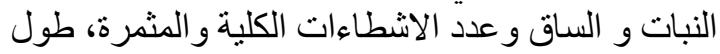

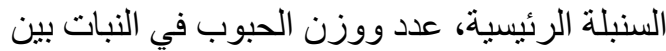

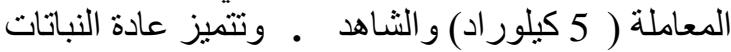
المتأخرة بالنضج بطول فترة النمو التطور وزيادة فترة
جدول(3): نباتات طافرة متوسطة الطول في الصنف فرات 1.

\begin{tabular}{|c|c|c|c|}
\hline المعنوية & كيلور اد 10 & الثاهد & المعيار \\
\hline 0.000 & ${ }^{*} 64.66$ & 90.66 & طول النبات \\
\hline 0.005 & *57.66 & 74.88 & طول الساق \\
\hline 0.022 & 9 & 8.99 & عدد الاشطاءات الكلية \\
\hline 0.024 & ${ }^{*} 8$ & 8.10 & عدد الاشطاءات المثمرة \\
\hline 0.031 & ${ }^{* 7}$ & 15.77 & طول السنبلة الرئيسية \\
\hline 0.007 & ${ }^{*} 163$ & 243.66 & عدد الحبوب في النبات \\
\hline 0.005 & *5.97 & 11.49 & وزن الحبوب في النبات \\
\hline 0.025 & ${ }^{*} 36.62$ & 47.16 & وزن الألف حبة \\
\hline
\end{tabular}

المتقدمة من النمو ، حيث لوحظ أن الفرق في مو عد التسنبل

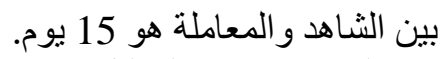

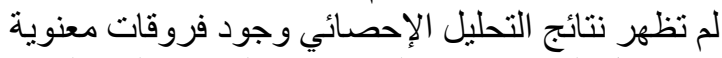

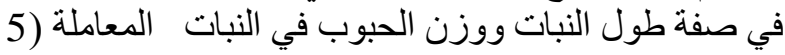

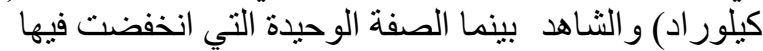

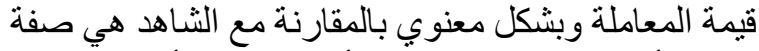
وزن الألف حبة، حيث ظهر التأثير المثبط للأشعة على هذئ هذه

الصفة بشكل واضح جدول (7) الأنة حطن

جدول (4): العلاقات الارتباطية بين الصفات المدروسة في الصنف فرات 1 تحت تأثير الجرعة (10 كيلوراد).

\begin{tabular}{|c|c|c|c|c|c|c|c|c|}
\hline المعيار & طول النبات & طول الساق & |الرئيسيةذ السنبلة & 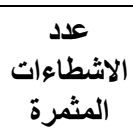 & الاشطاعات & في النبات & في الحبوب & وزن \\
\hline طول النبات & 1 & & & & & & & \\
\hline طول الساق & $0.996 *$ & 1 & & & & & & \\
\hline طول السنبلة الرئيسية & $0.940^{*}$ & $0.907^{*}$ & 1 & & & & & \\
\hline عدد الاثطاءات المثمرة & $0.926^{*}$ & $0.935^{*}$ & $0.824^{*}$ & 1 & & & & \\
\hline عدد الاثطاءات الكلية & $0.905^{*}$ & $0.899^{*}$ & $0.861^{*}$ & $0.976^{*}$ & 1 & & & \\
\hline عدد الحبوب في النبات & $0.935^{*}$ & $0.913^{*}$ & $0.953^{* * *}$ & 0.795 & $0.835^{*}$ & 1 & & \\
\hline وزن الحبوب في النيات & $0.927^{*}$ & $0.905^{*}$ & $0.946^{*}$ & 0.778 & $0.822^{*}$ & $0.996 *$ & 1 & \\
\hline وزن 1000 & $\mathrm{0.881}^{*}$ & $0.863^{*}$ & $0.885^{*}$ & 0.705 & 0.742 & $0.982^{*-}$ & $0.981^{*}$ & 1 \\
\hline
\end{tabular}


كما كان للأشعة تأثير مثبط في وزن الألف حبة حيث إثب

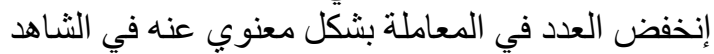

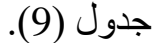

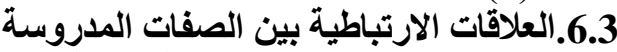

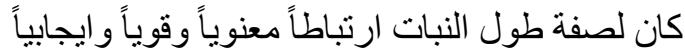

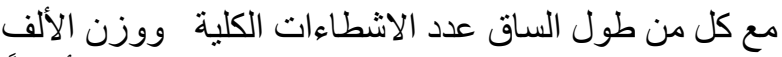

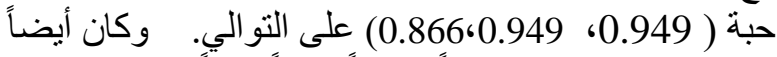
لصفة طول النبات ارتباطاً معنوياً وقوياً سلبياً مع عدد التي

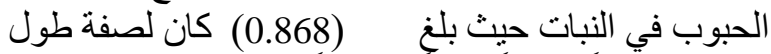

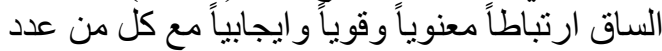

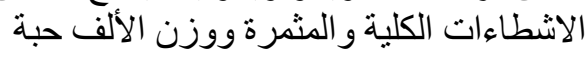

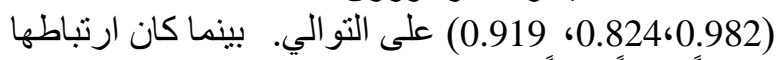
معنوياً وقوياً سلبياً مع عدد ووزن الحبوب في لئي
جدول(5): تحول السنابل من سداسية الصف إلى ثنائية الصف الصنف

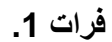

\begin{tabular}{|c|c|c|c|}
\hline المعنوية & 5 كيلوراد & الثـاهد & المعيار \\
\hline 0.014 & 93.32 & 90.66 & طول النبات \\
\hline 0.000 & 75.66 & 74.88 & طول الساق \\
\hline 0.001 & ${ }^{*} 12.33$ & 8.99 & عدد الاشطاءات الكلية \\
\hline 0.002 & *11.11 & 8.10 & عدد الاشطاءات المثمرة \\
\hline 0.045 & ${ }^{*} 17.66$ & 15.77 & طول السنبلة الرئيسية \\
\hline 0.004 & *305 & 243.66 & عدد الحبوب في النبات \\
\hline 0.007 & *12.11 & 11.49 & وزن الحبوب في النبات \\
\hline 0.007 & *39.70 & 47.15 & وزن الألف حبة \\
\hline
\end{tabular}

جدول (6): العلاقات الارتباطية بين الصفات المدروسة في الصنف فرات 1 تحت تأثير الجرعة (5 كيلوراد).

\begin{tabular}{|c|c|c|c|c|c|c|c|c|}
\hline المعيار & طول النبات & طول الساق & طول السنبية & الاشثطاءات & 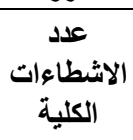 & في النبات & فزي النيات & وزن \\
\hline طول النبات & 1 & & & & & & & \\
\hline طول الساق & $0.979^{*}$ & 1 & & & & & & \\
\hline طول السنبلة الرئيسية & 0.511- & 0.670- & 1 & & & & & \\
\hline عدد الاشطاءات المثمرة & 0.808 & $0.839^{*}$ & $0.530-$ & 1 & & & & \\
\hline عدد الاشطاءات الكلية & $0.897^{*}$ & $0.906^{*}$ & 0.516- & $0.982^{*}$ & 1 & & & \\
\hline عدد الحبوب في النبات & $0.356-$ & $0.363-$ & 0.388 & $0.877^{*}$ & 0.560 & 1 & & \\
\hline وزن الحبوب في النيات & $0.941^{*}$ & $0.941^{*}$ & 0.535- & 0.738 & $0.835^{*}$ & 0.332 & 1 & \\
\hline وزن 1000 حبة & $0.935^{*}$ & $0.967^{*}$ & 0.661- & 0.778 & $0.850^{*}$ & 0.359- & 0.979* & 1 \\
\hline
\end{tabular}

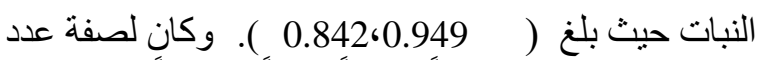

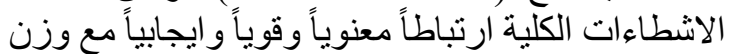
الألف حبة ( 0.869)، وارتباطاً معنوياً وقوياً وسلبياً مع كل

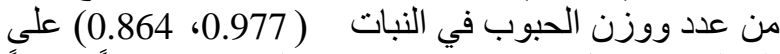

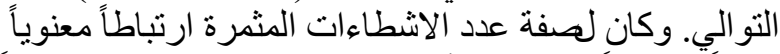

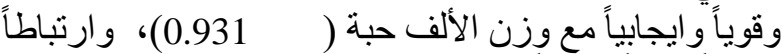

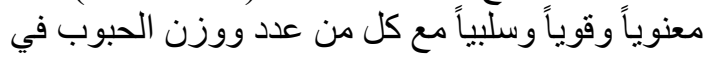
النبات (

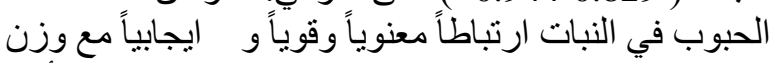
الحبوب في النبات (

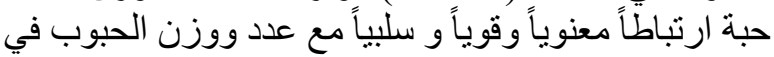

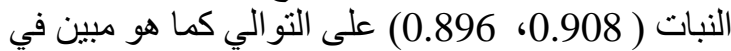

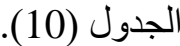

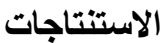

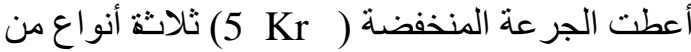

الطفر ات : تحول السنبلة من سداسية الصف إلى إلى ثنائية

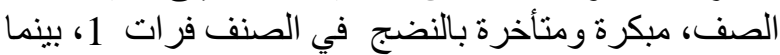

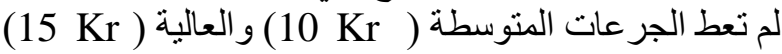

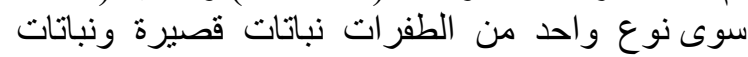
تحولت فيها السنبلة من ثنائية الصف إلى سداستية الصيرة الصف

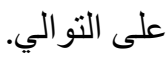

جدول(7): نباتات مبكرة بالنضج في الصنف فرات 1.

\begin{tabular}{|c|c|c|c|}
\hline المغنوية & كيلوراد 5 & الثاهد & المعيار \\
\hline 0.087 & 98.77 & 90.66 & طول النبات \\
\hline 0.042 & ${ }^{*} 91.77$ & 74.88 & طول الساق \\
\hline 0.020 & ${ }^{*} 13.33$ & 8.99 & عدد الاشطاءات الكلية \\
\hline 0.109 & 10.43 & 8.10 & عدد الاشطاءات المثمرة \\
\hline 0.476 & 6.96 & 15.77 & طول السنبلة الرئيسية \\
\hline 0.000 & *351 & 243.66 & عدد الحبوب في النبات \\
\hline 0.012 & ${ }^{*} 13.10$ & 11.49 & وزن الحبوب في النبات \\
\hline 0.002 & *37.32 & 47.15 & وزن الألف حبة \\
\hline
\end{tabular}

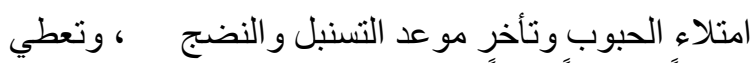

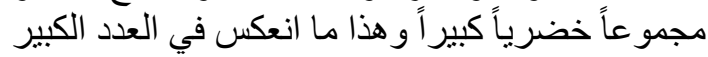

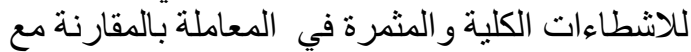
الثاهد، وتعطي منل هذه الطرز زئية فيادة في الاتتاجية الحبية

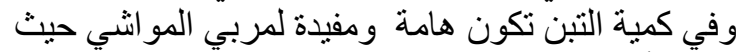
لوحظ أن الفرق في مو عد التسنبل بين الثـاهد و المعاملة هو لهو

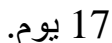


جدول (8): العلاقات الارتباطية بين الصفات المدروسة في الصنف فرات 1 تحت تأثير الجرعة (5 كيلوراد).

\begin{tabular}{|c|c|c|c|c|c|c|c|c|}
\hline المعيار & طول النبات & طول الساق & طول السنبلة & الاشثطراءات & الالشطاعات & في النبوبت & في الحبوبت & حزن 1000 \\
\hline طول النبات & 1 & & & & & & & \\
\hline طول الساق & 0.598- & 1 & & & & & & \\
\hline طول السنبلة الرئيسية & $0.971^{*}$ & 0.772- & 1 & & & & & \\
\hline عدد الاشطاءات المثمرة & 0.659 & 0.383- & 0.638 & 1 & & & & \\
\hline عدد الاشطاءات الكلية & 0.401 & 0.115 & 0.285 & $0.859^{*}$ & 1 & & & \\
\hline عدد الحبوب في النبات & 0.799- & $0.894^{*}$ & 0.900-* & 0.738- & 0.303- & 1 & & \\
\hline وزن الحبوب في النيات & 0.323 & 0.109 & 0.224 & 0.360 & 0.575 & 0.470 & 1 & \\
\hline وزن 1000حبة & 0.801 & 0.774- & $0.867^{*}$ & $0.820^{*}$ & 0.499 & 0.928-* & 0.402 & 1 \\
\hline
\end{tabular}

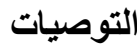

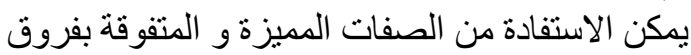

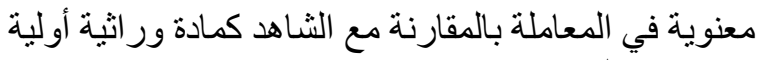

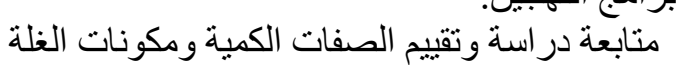

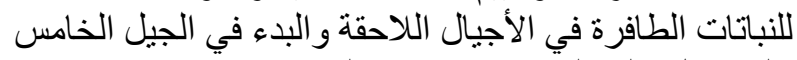

بالحصول على السلالات ومن ثم البداء بتجارب الإب الإنتاجية

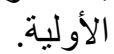

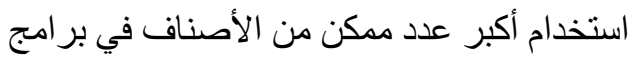

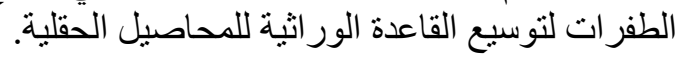

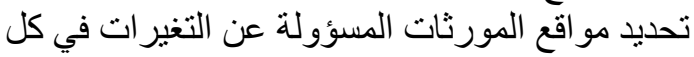

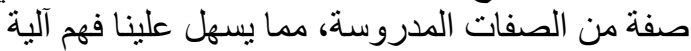
توريث هذه الصفات بشكل أفضل.
الجدول(9): نباتات متأخرة النضج باستخدام 5 كيلو راد من أشعة غاما

\begin{tabular}{|c|c|c|c|}
\hline \\
\hline المعنوية & كيلوراد 5 & الثـاهد & المعيار \\
\hline 0.021 & *95.77 & 90.66 & طول النبات \\
\hline 0.031 & $80.11^{*}$ & 74.88 & طول الساق \\
\hline 0.021 & *12.22 & 8.99 & عدد الاشطاءات الكلية \\
\hline 0.005 & ${ }^{*} 10.23$ & 8.10 & عدد الاشطاءات المثرة \\
\hline 0.026 & $16.66^{*}$ & 15.77 & طول السنبلة الرئيسية \\
\hline 0.033 & ${ }^{*} 439$ & 243.66 & عدد الحبوب في النبات \\
\hline 0.005 & ${ }^{*} 14.02$ & 11.49 & وزن الحبوب في النبات \\
\hline 0.005 & * 31.93 & 47.15 & وزن الألف حبة \\
\hline
\end{tabular}

جدول (10): العلاقات الارتباطية بين الصفات المدروسة في الصنف فرات 1 تحت تأثير الجرعة (5 كيلوراد).

\begin{tabular}{|c|c|c|c|c|c|c|c|c|}
\hline المعيار & طول النبات & طول الساق & الرئيسبية & الاشططاءات & الاشطاءعات & في الحبوبت & في الحبوب & حزن 1000 \\
\hline طول النبات & 1 & & & & & & & \\
\hline طول الساق & $0.949^{*}$ & 1 & & & & & & \\
\hline طول السنبلة الرئيسية & $0.245-$ & 0.527- & 1 & & & & & \\
\hline عدد الاشطاءات المثمرة & 0.805 & $0.824^{*}$ & 0.498- & 1 & & & & \\
\hline عدد الاشطاءات الكلية & $0.948^{*}$ & $0.982^{*}$ & 0.443- & 0.811 & 1 & & & \\
\hline عدد الحبوب في النبات & 0.868- ${ }^{*}$ & 0.949-. & 0.559 & 0.829-" & 0.977-* & 1 & & \\
\hline وزن الحبوب في النيات & 0.764- & $0.842-^{*}$ & 0.592 & 0.944-" & 0.864-* & $\mathbf{0 . 9 2 1}^{*}$ & 1 & \\
\hline وزن 1000حبة & $0.866^{*}$ & $0.919^{*}$ & 0.574- & $0.931^{*}$ & $0.896^{*}$ & 0.908- & 0.896- & 1 \\
\hline
\end{tabular}

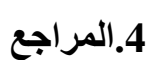

إحصائية الأمن الغذائي العربي( 2010 ).

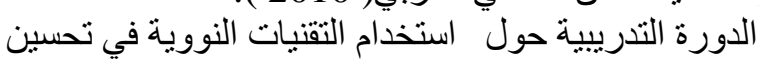

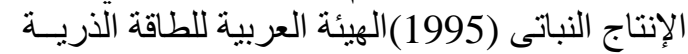

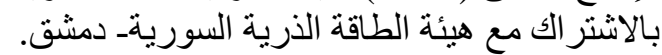

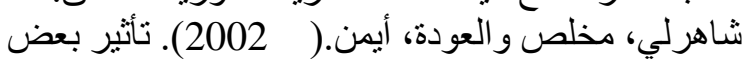

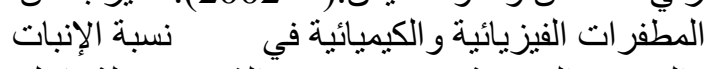

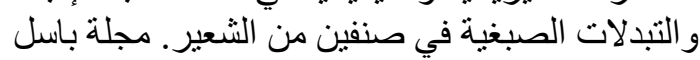
الأسد اللعلوم الزر اعية، دمشق فئن.
تأثر الصنف فرات بالأشعة بدرجة أكبر مقارنة مع الاكبر

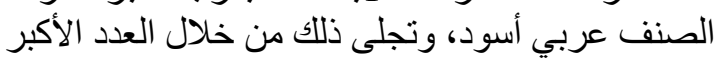

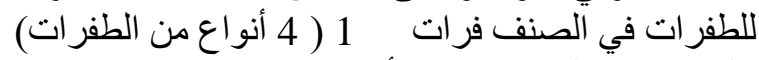

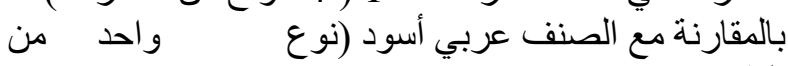

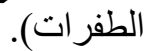

تميزت بشكل عام علاقات الإرتباط بين الصفات

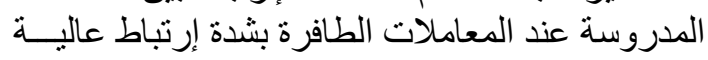

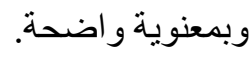




\section{REFERENCES}

Chen Y.(1996). Anther and pollen culture of rice, p. 3-25. In: Haploids of Higher Plants In Vitro. $\mathrm{Hu}, \mathrm{H}$. , Yang, H. (Eds.). Springer-Verlag, Berlin

FAO (2010). Statistical report of 2010.

Förster N. M., Doyon R., Nadeau D. and Rowlands N.(1994). Infrared Astronomy with Arrays: the Next Generation, ed. I. S. McLean (Dordrecht: Kluwer), 509.

Franckowiak J.D. (1995). The brachytic class of semidwarf mutants in barley. BGN 24:56-59.

Irfaq M. and Nawab K.(2003). A study to determine the proper dose of gamma radiation for inducing beneficial genetic variation in bread wheat (Triticum aestivum L.). Asian Journal of Plant Sciences 2 (13): 999-1003.

Jain K.B.L. (1961). Genetic studies in barley. III. Linkage relations of some plant characters. Indian J. Genet. Plant Breed. 21:23-33.

Koksel H., Celik C. and Ozkara R.(1998). Effects of gamma irradiation of barley and malt on malting quality. Journal of the Institute of Brewing, vol. 104, n2, pp. 89-92.

Komatsuda T., Pourkheirandish M., Congfen H., Azhaguvel P., Kanamori H., Perovic D., Stein N., Graner A., Wicker T., Tagiri A., Lundqvist U., Fujimura T., Matsuoka M., Matsumoto T. and Yano M. (2007). Six-rowed barley originated from a mutation in a homeodomainleucine zipper I-class homeobox gene. Proc. Natl Acad Sci. 23; 104(4): 1424-1429.

Lundqvist U., Meyer J. and Lundqvist A.(1991). Mutagen specificity for 71 lines resistant to barley powdery mildew race-D1 and isolated in 4 hybrid barley varieties. Hereditas 115:227239.

Maluszynski M., Micke A., Sigurbjörnsson B., Szarejko I. and Fuglewicz A.(1987). The use of mutants for breeding and for hybrid barley. In: Barley Genetics V. Proc.5th Int.Barley Genetics Symposium, Okayama (Japan) 1986. pp.969-977.

Pozzi C., di Pietro D., Halas G., Roig C. and Salamini F. (2003). Integration of a barley (Hordium vulgare) molecular linkage map with the position of genetic loci hosting 29 developmental mutants. Heredity 90:390-396.

Sears R.G., Kronstad W.E. and Metzger R.J. (1981). Inheritance of dwarf and semidwarf plant height in barley. Crop Sci. 21:828-831.

Zoshchuk1 N. V., Badaeva1 E. D. and Zeleninl A. V.(2003). History of Modern Chromosomal Analysis. Differential Staining of Plant Chromosomes. Russian Journal of Developmental Biology, 34:(1), 1-13. 